This is an Accepted Manuscript of an article published by Taylor \& Francis Group in Technology, Pedagogy and Education, available online:

http://dx.doi.org/10.1080/1475939X.2016.1217269

Chris Shelton (2017) Giving up technology and social media: why university lecturers stop using technology in teaching, Technology, Pedagogy and Education, 26:3, 303-321, DOI:

10.1080/1475939X.2016.1217269

\title{
Giving up technology and social media: why university lecturers stop using technology in teaching
}




\section{Abstract}

University lecturers use a wide range of technologies when teaching and there has been much research into how particular technologies are adopted. However, there are also many technologies that, despite early promise, are no longer being used in university teaching and have been abandoned by institutions or individuals.

This paper presents the results of a qualitative investigation into why university lecturers stop using technology. It used detailed episodic narrative interviews to explore the experiences of lecturers using technology in their teaching at three UK universities. While the data provides examples of technologies that were discarded as they became out-dated and were replaced by new devices, this was not the only reason that technologies are rejected. The data also demonstrated that even relatively up-to-date or innovative technologies or practices (e.g. the use of Facebook) may be abandoned.

The paper discusses the participants' experiences of ceasing to use technology and demonstrates the importance of context in decisions about using technology and social media in teaching.

The paper argues that studies of technology adoption should be accompanied by research that re-visits the sites of these studies to consider how the implementation of technology continues over time and how it comes to an end.

\section{Key Words:}

Technology adoption, integration, implementation, higher education, lecturers 


\section{Introduction}

Although there have been many studies into the adoption of new technologies for teaching and learning in higher education, comparatively few researchers have considered how or why individuals stop using technology.

Research about non-users of technology may be framed in terms of concerns about access to certain technologies or internet services and 'digital divides' between those with or without such access. However, even those (like university lecturers) who have relatively easy access to technology and may use it frequently, occasionally make decisions to stop using particular technologies. Sometimes this is because an older technology, e.g. the Video Cassette Recorder, has been superseded and replaced but, as this paper will show, this is not always the case and even relatively new technologies, such as Facebook, may be adopted and then discarded. This article is therefore not about non-users of technology but about the decisions that users make about the specific technologies they use. In particular, it considers lecturers' experiences of using technology in their teaching and the reasons they give for ceasing to use specific technologies.

\section{Adoption and non-adoption of technology in Higher Education}

From the 1940s, universities have experimented with a wide range of different educational technologies, including radio, television and film (Kay, 1979) but although these technologies continue to be used in some form, it can be argued that many have not lived up to the potential originally claimed for them. While it is claimed that using technology can lead to fundamental shifts in academic practice (Weller, 2011), much of the use of technology in higher education has served to replicate or supplement existing 
practices rather than extend or transform teaching (Kirkwood, 2009). In a familiar pattern, many innovations have been accompanied by claims for their potential impact, 'proven' through small-scale examples of effective practice but then failed to produce the radical sector-wide improvements that some had hoped for, leading to a 'digital disconnect' (Selwyn, 2007), between the enthusiastic rhetoric and the reality of technology use in higher education.

In explaining the relationship between the introduction of technology and teaching practices, Kanuka and Rourke (2008) note that technology is not a neutral tool but rather that it can "amplify certain aspects of the teaching and learning environment while reducing others" (p6). Their research identified several areas where technology can both enhance or reduce or practice (p13-14), for example, they suggest that technology may improve access for students by removing geographical barriers but in doing so, can inadvertently lead to a loss of a sense of belonging.

Whilst we need to be careful not to suggest a 'technological determinist' view that technology itself has the power to cause social change, it is clear that none of these claims for technology can be properly evaluated if that technology is never used. Therefore, a large body of research exists that explores the factors that affect whether or not particular technologies are adopted by university lecturers. For example, Davis et al.'s (1989) Technology Acceptance Model (TAM) and its successors such as Venkatesh's (2003) Unified Theory of Acceptance and Use of Technology (UTAUT) have been widely used and adapted by researchers investigating the factors that lead to a range of different technologies being adopted in Higher Education (see, for example, the 
42 studies reviewed by Šumak, Heričko and Pušnik, 2011). Such studies are concerned with the factors that lead to the initial adoption of particular technologies and, in the case of TAM, how these relate to the perceived usefulness and perceived ease of use of that technology. According to Rogers (1962), if we consider a particular technology then we can classify users into groups according to how quickly they adopted the technology. While the first users (the 'innovators' and 'early adopters') are characterised by positive attitudes to technology, those who are slower to take up the technology (the 'late majority' and 'laggards') may be characterised by less positive attitudes to technology. This model is extended by West, Waddoups, and Graham (2007) who identify how following a period of experimentation, lecturers may choose to continue, reduce or discontinue their use of a technology. In their study, discontinuation of the Blackboard Virtual Learning Environment was associated with increased use of alternative technologies. This paper develops this avenue of research by considering why lecturers who originally chose to implement a technology later ceased doing so.

There are a number of potential explanations for such decisions. For example, a body of work has identified 'barriers' that may mitigate against the successful adoption of technology or 'enablers' that support it (e.g. Kidd 2010). For example, Bakioglu and Hacifazlioglu (2007) and Brill and Galloway (2007) both suggested that lecturers in their studies felt constrained by a lack of equipment. However, such studies do not usually consider why lecturers who have overcome these 'barriers' and adopted a technology subsequently cease to use it. An exception is Agbatogun (2013) who suggests that university faculty are unlikely to continue to use technology in their teaching if they 'encounter difficulty' (p352). Some of these potential 'difficulties' are identified by 
Cramp (2015) who notes that while there has been concern about student experiences with technology, less has been written about the experiences of lecturers "whose early experiences with digital pedagogies can involve extra work and stress, some fundamental shifts in pedagogic approaches, high levels of risk and exposure to change which can lead to some significant professional vulnerabilities" (p6).

In addition, although models such as 'TAM' assume that lecturers' attitudes towards a technology affect how they use technology, the evidence for this is less clear. For example, Bothma and Cant (2011) describe a set of university lecturers who were in favour of using a learning management system but did not actually use it. In other cases, individuals may have little choice as to whether or not to continue to use a technology (Shelton, 2014).

There is also a large body of research that considers the relationship between lecturers' pedagogic beliefs and their use of technology. Welsh (2012) describes how the introduction of an e-portfolio to an undergraduate module played a crucial role in enabling the new forms of assessment and increased student self-regulation that the module leaders intended. Here, the uses of the e-portfolio were aligned with the pedagogic beliefs and intentions of the lecturers. In contrast, Westberry, McNaughton, Billot, and Gaeta (2014) show how when a technology (in this case video-conferencing) is introduced without regard for lecturers' pedagogic beliefs, it may lead to tension and resistance. In this case, some lecturers found the change 'disorientating' and conceded aspects of their preferred pedagogic approach. Westberry notes that over the year that the technology was used, there was a growing reconciliation between the lecturers and their 
use of the technology but eventually "the lack of professional development opportunities for staff and daily technical breakdowns led to replacement with another system" (p110).

In summary, there is a strong body of research identifying factors that influence lecturers' initial decisions to adopt technology. The aim of this study is to build on this by considering how university lecturers experience ceasing to use a technology and how they explain the decision to do this.

\section{Methods}

The data for this research was collected as part of a qualitative multi-site case study investigating university lecturers' thinking about technology. The research sought to generate narrative biographies of lecturers' engagement with technology through an 'episodic interview' method (Flick, 2009). This uses a 'generative question' - in this case a prompt to elicit the participants' experiences of being a learner and a teacher and how technology had played a part in this. This was followed with phased prompts that encouraged participants to give a chronological account of their experiences. The resulting individual narratives allowed investigation into how participants' reported uses and perceptions of technology had changed over the course of their career. They also identified significant events and technologies and revealed some of the influences on an individual's use of technology. In particular, participants were asked to identify any technologies that they no longer used and to explain why this was.

After an initial pilot, research interviews were conducted with eleven university lecturers based at three English universities. These universities were all "post-92", modern, multicampus universities based in three different cities. Participants had a range of teaching 
experience and seniority and came from different disciplinary backgrounds (See Table 1). In order to maintain participant confidentiality, interviewees have been assigned a single letter code.

All interviews were transcribed and coded. An initial open coding aimed to construct analytic codes through a close reading of the text. Charmaz (2006) suggests that the purpose of this initial coding is to 'mine early data for analytic ideas to pursue in further data collection and analysis' (2006, p. 44). A second stage of coding applied the themes identified across the interview data.

Participation in the research was entirely voluntary. All participants were fully informed of the purposes and intentions of the research at the outset of the data collection and gave written consent. Participants were also free to withdraw from the research at any point during the research process and were reminded of this before taking part in the interviews.

\section{Findings and Discussion}

Several themes emerged from the interview data and participants discussed three situations in which they ceased to use a particular technology. These were: where technologies that they had previously used successfully had been replaced by a newer technology; following unsuccessful experiences with technology; and when there were changes in the context in which they worked. Each of these are discussed in turn below and then related to the specific case of giving up social media. 


\section{Replacement technologies and the limits of personal agency}

Of the eleven participants in this study, only one could not recall a technology that they had previously adopted but no longer used. This was the only participant who had less than five years experience of university teaching $(F)$ so it might be suggested that he had had less opportunity to adopt and then stop using technology than more experienced lecturers. Each of the other participants was able to identify at least one technology that they had used in their teaching previously but had now given up using because it had been replaced by a newer technology. For example, audio recordings (mentioned by Interviewee $\mathrm{G})$, VHS video (E), vinyl records (J), CD and DVD data storage (K) had all been superseded over the careers of participants.

In some cases, the new technology was thought to be a clear improvement over the technology it replaced. For example, Interviewee B described himself as an 'early adopter' (interviewees B and $\mathrm{H}$ were the only participants who would describe themselves this way) and was able to discuss a number of different technologies that he had adopted or discarded over his career. In one particular case, he recounted how he had previously used a multimedia authoring tool to create complex animations that illustrated concepts in psychology. He had stopped doing this because he felt that much 'richer' resources were now available. These were superior to the older technology in several ways: they did not require as much investment of his time to create and were of higher quality than the 'half-baked animation' he had created himself.

In other cases, however, replacement technologies were characterised not as being 'better' as much as just being 'new'. For example, Interviewee E described changing to 
new technologies because they were now available rather that because of any limitations with the older technology. Because these technologies were directly replaced, ceasing to use the old technology had no significant impact on teaching and they were not 'missed':

You just get new stuff and then the old stuff seems slower or I think things become outdated not because they themselves lose function but because there's new stuff so you switch. (E)

The most frequently discussed example of replacement was the transition from using slide transparencies on overhead projectors (OHPs) to using Microsoft Powerpoint on computer data projectors. Seven interviewees (A, B, C, E, H, J, K) recalled using OHPs and then replacing these with Powerpoint presentations as the technology in their teaching rooms was developed. Replacing this technology was perceived both positively and negatively. When participants reflected on their experience of using OHPs, they identified a number of limitations of this older technology when compared to their current practice. For example, OHPs were described as presenting unclear images and being inconvenient:

Well they just couldn't see it properly, the contrast was all bad, the lighting in the room just doesn't work, so the image size was all terrible. (K)

[Digital projectors] are just more convenient and you don't have the whole wonky thing with the OHP. They are like fun aspects aren't they, where it keeps falling off or whatever. Then there is the whole noise thing, with the OHP whirring away with its fan ... I don't miss them. (E)

However, participants also identified some affordances of OHPs that they missed. For example, the ease with which they could be annotated $(\mathrm{K})$ and these notes projected, 
copied and shared (C). Not all participants had been keen to stop using OHPs at first. Interviewee $\mathrm{H}$ described how she had been very reluctant to stop using her OHP slides and continued to use them even after digital projectors became widely available. In her case, it was the reaction of her students that proved the decisive factor:

Kids laugh, they think it's an antique. 'Really, that's so retro!' (H)In addition, the process of replacement can be problematic. Participants recalled some of the challenges they encountered when moving from OHPs to Powerpoint. Interviewee $\mathrm{C}$ and $\mathrm{K}$ recalled difficulties replacing images that they had used and having to create their own.

The nice thing about OHP slides is you can just photocopy them. So if you have got a text image, I used to photocopy out of a book, cut the image out and just photocopy it onto an OHP slide. You can do the same today but you've got to go through the whole kind of scan process which I don't, I must admit. Yeah, so if there is an image in a textbook I would have normally used as an OHP slide just because I could copy it, then copy it onto an OHP slide, I don't do that anymore. I either redraw the image myself or I find some sort of version of it. (C)

While this participant acknowledged that a replacement process (scanning and import) was available instead of the original process (cut and copy onto transparency), this particular lecturer adopted the newer technology without adopting the new processes that might accompany it. This could be frustrating as another interviewee described:

For some sessions I just couldn't find images or photographs or illustrations of the points that I needed and having to try to do them and try to doodle stick drawings on word and things like this which was a complete pain because I am artistically deficient at best. So yes it was time consuming and annoying and all the bits that linked together in the software didn't really work together. The end product, if you 
had all the resources, the end product would be good, but if you didn't it was time consuming. (K)

A similar issue was described by Interviewee $\mathrm{J}$ regarding the replacement of vinyl records and VHS videos. While she recognised the need to convert these to newer formats, she felt that this was more complicated than before. While she had previously learnt VHS video-editing skills, these were now obsolete and had not been able to find the time to learn the new skills that are associated with digital editing.

On other occasions, the loss of a technology had been both unwelcome and unexpected. Interviewee $\mathrm{J}$ described writing on whiteboards during her lectures but being forced to stop doing this because her institution removed whiteboards from their teaching spaces:

I walked into the same room that I have always been teaching in and it was like wow it's gone. Sorry guys I can't write my name on the whiteboard you will just have to wait for me to faff around and get this Powerpoint going so these people are just sort of staring and going, well, who's that then faffing around. So because usually I write on the whiteboard, so this is my name, this is where you can contact me and this is the name of the session and just in case you might be completely confused this is the module and then that would be on the whiteboards continuously while I actually discussed stuff because there is always someone who misses. ( $\mathrm{J}$ )

This episode demonstrates the lack of control over their technology use that some participants expressed - the non-digital technology (whiteboards) had been taken away possibly because the computer projection screen was available for the perceived use (communication with students) but this participant was unaware that this replacement was about to happen and preferred the existing (non-digital) technology. Similarly, the introduction of digital projectors happened despite some lecturers feeling that some 
aspects of the older technology had been useful. It would be easy to present the replacement of older technologies and practices with newer, more advanced ones as an inevitable consequence of progress. And, the data here does provide some support for this with examples of individual users replacing technologies by something believed to be 'better' in some way or maybe just 'newer'.

But this optimistic narrative of progress would conceal the actual process happening in these stories of replacement technologies. In fact, these stories highlight the limited personal agency felt by university lecturers in their decisions about teaching with technology. Replacing a technology does not always imply that this was done voluntarily or that there existed a willingness to replace the processes that are used with the older technology or to develop new skills that may be required. In addition, the examples of the OHP and whiteboard above demonstrate that university lecturers may not always be willing to adopt new technologies even when it is intended as a direct replacement for an existing tool. Such decisions highlight that individuals may not feel that they have a great deal of personal agency in their decisions about what technologies to use but may perceive technological choices as being made for them by those who are responsible for purchasing and maintaining equipment. In fact, a closer consideration of the narratives of replacement, shows that for some at least, the adoption of new technologies may be accompanied with a loss of something felt to be important. This is in line with Kanuka and Rourke's (2008) claim that technology can both amplify and reduce aspects of teaching.

If we revisit research that studied the introduction of Powerpoint when digital projectors first became prevalent, we can find a number of early studies comparing similar courses 
taught with or without Powerpoint. These tended to note that students reported positive attitudes towards the use of Powerpoint (e.g. Cassady, 1998) although, as Craig and Amernic (2006) point out, the 'novelty factor' that may have affected those early studies will no longer have a positive effect on students' attitudes. However, some of these early studies recognise that there may be losses as well as gains, for example, Szabo and Hastings (2000) conclude that: "PowerPoint should not be viewed as a replacement for the blackboard, but rather as an efficient auxiliary medium, that can improve learning."

The feelings expressed here about what has been lost as the technology has been abandoned leads to questions about what older technologies might still have to offer. A similar idea can be found in the following quote which reflects on another technology that may not be used to its full potential:

One of the things that I've not seen used recently is television which is amazing. Obviously the media people use it because they study television. But there are still some good things that people could use if they [pause]. So I think, my point would be, if we use the basics better, we'd have a better set of materials available. (D)

\section{These sentiments suggest that there would be something to be gained from reconsidering the usefulness of older technologies and the later section regarding context goes some way towards explaining why this has not happened.Unsuccessful experiences with technology}

While the examples above describe technologies that were, to some extent, working successfully before being replaced, in other cases individuals may cease to use a technology because it is not successful. Perhaps unsurprisingly, when technologies were new and still being explored and experimented with, any problems were likely to affect 
decisions about their future use or even lead to avoiding using that technology:

I think there is like a bit of a natural inhibition when you are trying to use something new and if it doesn't work or you are not quite $100 \%$ confident, there is a bit of an avoidance (E)

As an example of an unsuccessful experience of using technology, Interviewee $\mathrm{K}$ recounted teaching a module online whilst on sabbatical:

I tried to do a module purely through [institutional VLE] and chat rooms and giving electronic versions of papers and discussions and it didn't work at all. People would sort of $\log$ in and pretend they were there. They weren't really interactive. Didn't do the work they were supposed to because there is no-one there to watch them. So yes, I also found that for the content, for what they got back, I had to work twice as hard as I would do if I was here delivering it. I had to do twice as much behind the scenes, so it was very time intensive. (K)

Given that Interviewee $\mathrm{K}$ felt that he had worked twice as hard but students had not engaged, it is perhaps not surprising that he was not keen to teach this way again. Such negative experiences could have a long-lasting effect and Interviewee B suggested that 'some people have got long memories' where unsuccessful institutional use of technology was concerned.

However, it is not the case that unsuccessful experiences routinely led to decisions to cease using a technology. In fact, the most common examples of unsuccessful experiences were occasions when presentation technology or internet connections in a participants' teaching room failed to work. Sometimes this had led to a session being cancelled $(\mathrm{C})$, to delay and inconvenience $(\mathrm{G})$ or to a perception that they had lost credibility in the eyes of their students $(\mathrm{K})$. But although these events were frustrating at 
the time, they did not lead to any participant abandoning that technology altogether and appeared to have had no long-term effect. And while some (e.g. Interviewee C) recalled lecturers who had kept backup OHP slides in case of problems with digital projectors, they felt that this practice had now died out. Similarly, other problems with established technologies, e.g. email (C, D and J), were treated as annoyances and exceptions.

So a lot of the time and effort spent doing electronic things is time wasted. Email being the classic amount of time spent on pointless emails, well it seems like nothing and people always complain about the number of emails. But it is an unproductive way of spending the time. (D)

Yes sometimes I find that people seem to think that if they send you an email it's already served, like I have an antennae in my brain and I just know what they are saying, (J)

One factor that affected whether an unsuccessful use of technology led to abandoning that technology or was just treated as an annoyance was how the lecturer explained their lack of success. Participants attributed their disappointments or failures with technology to a number of different causes. For example, two participants discussed how their initial enthusiasm for online discussion forums had turned to disappointment due to the lack of response from students ( $\mathrm{E}$ and $\mathrm{I})$. For Interviewee I, this decision was due to problems with the technology - she felt the forums compared poorly both with the quality of discussion in face-to-face classes and with other methods of online communication and led to superficial responses.

My experience with discussion boards is that they don't like it, it's not a replacement for seeing your face on Facebook, that's not how we would want to use it anyway but they don't. Very, very few of them engaged with it. (I) 
Interviewee $\mathrm{E}$ also compared forums to another technology, in her case, email:

I created forums, one example is for them to ask me questions about assessments purely so I didn't have to answer the same question 60 times to try and be efficient. And normally if anything inspires them to do something it is normally something around assessments. No, they didn't use it ... it is easy for them to fire you an email going what's this, what's that. (E)

But she was insistent that despite the poor response, she would use forums again and reflected on how she could improve her use of forums in the future suggesting that she had been 'naïve' in expecting a better response without doing more to make the forum work.In one case, an interviewee described a range of unsuccessful experiences and the different ways that he had reacted to these. Interviewee B described how he had learnt from some of his unsuccessful experiences and viewed these 'disasters' as important lessons. He believed that his students did not mind if technology failed but appreciated that he had tried to do something different for them:

Students like it when you make an effort. I don't think, students don't even mind if it fails, they really appreciate that you've tried to do something a little bit different for them. That's not necessarily technology although it often is (B)

His response shows how he cared about the reaction of his students but also that he could find a positive outcome from technological failures.

These examples show that sometimes failure with technology may lead to that technology being abandoned but that this is not the only possible consequence. On the contrary, it is not possible to make broad generalisations about the effect of unsuccessful experiences on an individuals' use of technology in teaching. In common with West, et al. (2007) and 
Abagotun (2013) the data shows that problems at the earliest stages of technology adoption can lead to discontinuing use. However, this data differs from earlier studies in showing that this can change once the technology has become a more established part of their teaching. The participants attributed their lack of success to a range of different causes including limitations of the technology itself and their own expertise. As in the previous section, the narratives demonstrate differences in the agency that individual had about their use of technology and their freedom to take risks and to fail.

\section{Contexts for giving up technology}

The examples above show that university lecturers sometimes give up using a technology when new technologies appear or after unsuccessful experiences and that this may or may not be a voluntary decision. A third situation where a lecturer may choose to cease using a technology related to changes in the context in which they work and such changes help to account for involuntary decisions to cease using technology.

For example, a particular use of technology might be discarded because, over time, it had become perceived as less relevant or useful for students. Both Interviewee B and J described how they had once provided students with links to websites that they thought would be useful for them. But as students presented themselves as more sophisticated and skilled users of technology, they had less need to do this 'because they tend to find them

for themselves' (B). Interviewee J now saw that practice as 'old-fashioned' because 'links are everywhere'. Similarly, Interviewees E and G described running introductory courses to help students use technology that they no longer felt were needed: 
I remember a long time ago, we used to have courses in how to use the internet. You can't imagine it now really and students coming in and showing them how to do a web page and things like that. Stuff that is just bonkers now, you would just never do that. But we do show them how to make posters, research posters and things like that. (E)

Here, it was not the technology itself that had been superseded but rather the particular application of it changing as the lecturers' perception of the capabilities of their students changed. Thus the decision to abandon this particular way of using technology reflected changes in the context in which these individuals taught.

Sometimes the reason for stopping could be caused by changes at an institutional level. Interviewee I described two different technologies that she had used successfully in the past. One of these was a wiki:

It was a problem based learning module, so the students were posed a case study and had to go and find information and share that information. And the Wiki actually did work, it was quite a good vehicle for them to share what they had found out information wise.(I)

In this example, the technology was felt to be well-matched to the pedagogic approach of problem-based learning and to work better than the alternative of using the VLE. However, when the module finished, the technology was no longer required:

We re-validated and we had to lose something and that was unfortunately what we lost.

So do you think you might do something with a wiki again?

Yes. I mean it did work well actually but it is finding the right place to use it, I'm not a fan of using things for the sake of using it, of it being available. 
In a different example, Interviewee I recalled how, having designed an innovative set of multimedia course resources, her university provided students with an iPod containing these for use on work placements. Although she believed that these were still very useful, this practice had stopped shortly before she was interviewed. She attributed this to changes in the financial context but also to the wider availability of such devices and smartphones amongst students.

For the first couple of years we were giving it to them on an Ipod. We haven't done that this year and that is largely for financial reasons really. But also because when we first started doing this two or three years ago very few students appeared to have devices, MP3 type devices, that this sort of thing would play on whereas now nearly all of them when we ask them appear to have this sort of device. (I)

Sometimes, participants noted the early warning signals that a technology was reaching the end of its life in their teaching. In one interview, a lecturer described how they used video clips from YouTube in their teaching sessions but had begun to reduce the frequency of these. This was not because the video clips had become less useful but because of how she believed her students perceived this practice:

I think some of the students perceive it as really lazy. I think two years ago, I pulled out my old, goodness knows what it was, probably from Victorian literature, a clip, an adaptation of Jekyll and Hyde, I think, and as I clicked out of Powerpoint, because I hadn't worked out how to get out though links at that stage, and into YouTube, I heard a young man about three rows from the back audibly groan 'Oh, YouTube, god'. And I felt like such a cheapskate, I really did and it's made me think. And now if I ever show a YouTube clip in a lecture and it's becoming less and less frequent, it's always with an apology, a sort of ironic, hey kids, look at me, I'm using new-fangled YouTube. They'll go urghh but you fronted it out with that. So, yes, really interesting that that's happening. $(\mathrm{H})$ 
In response to her perception that students regarded YouTube as 'lazy' and 'a cliché', she did not abandon the technology but used such video clips less frequently and presented them apologetically and ironically.

The context in which a technology is used is important and can even have consequences outside of the immediate situation. Interviewee D was particularly concerned about the overuse of Powerpoint presentations and refused to use Powerpoint slides in his university teaching. This was not due to a lack of skill but rather a concern about the quality of communication. Although he had previously used Powerpoint, he traced his rejection of the technology to a particular time and place:

There was a particular moment, categorically, we were doing promotions for a then diploma in Higher Education Policing to the police. And what we realised talking to the police was that people associated powerpoint presentations and that flashness with insincerity. So we decided to abandon powerpoint when we did our presentations and just sit and talk and it was good, it worked. But that was a conscious decision about people's response to marketing techniques and people have become wary of being sold a pup through powerpoint and flashing lights. And just relaxing and talking was more effective. So that was about 2000. So you can almost date it and it was very successful that strategy. (D)

As this excerpt shows, a concern for how an individual presents themselves through technology (in this case as too 'flash' or 'insincere') can lead to a decision to reject that technology. In addition, in this case the decision to abandon Powerpoint in this specific context (promoting a course to a particular audience) was transferred to a decision about teaching in other contexts.

These examples show how the context in which individuals worked and taught affected 
their decisions to stop using technology. These contexts include institutional and financial constraints but also lecturers' perceptions of the skills and interests of the students they taught. Research into technology adoption has shown how institutional and infrastructure factor can be a 'structural constraint': a barrier or enabler to the use of new technologies (e.g. Buchanan, Sainter and Saunders, 2013) while Zhu (2013) suggests that the organisational culture of universities is an important factor in how technology is implemented. The examples here support these claims by demonstrating that the immediate institutional context is relevant for understanding why lecturers give up technologies as much as for understanding why they adopt them. In addition, these examples go further and demonstrate the relevance of the ways students use technology in their lives outside of university to lecturers' decisions. As the next section will show, the role of this wider context can be seen most clearly in the accounts provided of participants ceasing to use social media.

\section{Giving up social media}

The use of computer mediated communication and social media have had a high profile in research on using technology in higher education. Technologies that support online collaboration and dialogue are highlighted as having particular potential for education (e.g. Booth \& Hultén, 2003) and the use of social media, such as Facebook, as an educational environment is claimed to improve classroom practices and student involvement (Aydin, 2012). Therefore, it is particularly important to consider why some university lecturers choose to stop using these.

Ten of the participants had previously used some of the communication functions within 
their institutions' virtual learning environments (VLEs). While no participant had completely stopped using their institutional VLE, some had reduced their use of tools within the VLE that allowed for asynchronous discussion amongst students. This could be thought of as due to lecturers' replacement of the institutional systems by external social media, however, the individual accounts also illustrate how the experience of using social media is shaped by social practices.

For example, Interviewee $\mathrm{H}$ described how she had once used discussion forums within her institutional VLE to create a social space where students could communicate. This was intended to give students some degree of ownership over their online module page. She described how this had initially worked well and students were willing to use the VLE to communicate and to take some ownership of the discussions. However, this practice ended as first MySpace and later Facebook became popular:

From that point, that willingness declined and the sense of wanting to keep communication with other students, on the students' part, off-line and outside the VLE, got stronger and stronger and it's very hard to break through now. $(\mathrm{H})$

Interviewee H respected her students' desire to separate their social communications and their learning and recognised that students had a growing sense of their online identities. In this case, the students had replaced the institutional technology (the VLE) with their own choice of technology (Facebook) reflecting increasing use of social media in wider society.

This increasing use of social media also raised challenges for teachers, for example, Interviewee B remarked on the ways that students used Facebook to criticise lecturers 
during taught sessions:

Interestingly because I'm a Facebook friend of quite a lot of our students I was coming in on the bus one day, so this wasn't my session, but I was coming in on the bus to read a Facebook post by one of the students talking about how boring what they were sitting in was and I'm under no illusions that there are others doing that when I'm lecturing as well. (B)

As institutional VLEs were replaced as a method of communication between students, some participants began to adopt the social media that students did use into their teaching. But given students' concerns about the overlap between their home and study lives, it is perhaps unsurprising that student-initiated uses of Facebook were described as more successful than those led by university staff $(\mathrm{J})$ and less likely to raise ethical questions about professional relationships between lecturer and student (D).

Whether or not a university lecturer used Facebook was also influenced by their institutional context. Interviewee $\mathrm{G}$ described how she had used both Facebook and Skype to communicate with students. She was very positive about the benefits that these had brought and felt that social media had enabled her to build relationships with students. However, she had stopped using these tools when she moved to her current institution. In the case of Skype, she had been unable to download the software onto her university computer and there were technical barriers preventing her continuing to use this. In contrast, there were no technical reasons that she could not continue to use Facebook but she had believed that she was not allowed to use it at her institution.

I know that in this University we don't use Facebook. I used to use Facebook and it worked for me. Simply they haven't attended, the deadline of the submission is a week, go on Facebook and I see her on Facebook. And they go, I'm really sorry I 
haven't done the hand in and they do hand in because they are so embarrassed. So it's a gentle reminder but as I said I don't use it with the current students here but I was allowed to use at [previous university].

\section{Was that because you are not allowed to use it here?}

I was told that, they didn't use the word allowed, it was used 'not suggested'. So I am not using it. (G)

As the interview participants included four interviewees at this university, it became clear that some other individuals at the same university were using Facebook with their students. This example shows how unwritten expectations can exist outside of official university policies and how departmental or peer relationships can influence university lecturers to cease using technologies that they believed to have had a positive impact on their teaching.

While institutional rules or expectations and students' views of their digital identities were key considerations for lecturers' use of social media, participants' perceptions of how social media affected their relationships with students were also important. Some participants were able to make use of Facebook in their work and manage their professional relationships successfully. For example, Interviewee J's students had created their own course page on Facebook and kept ownership of this:

What has worked really well is my First Years set up a page on Facebook that they set up, I didn't and that makes it very different. It's their site, they organise it, I'm not a member of it but I can actually see it because they like to be allowed but, and it's a mixture of things that they like to listen to or watch as well as stuff that they have produced themselves. And sometimes it is like, slightly unfinished things and they just want comments on it. Just the way that you want the forum to work really but because it is generated by them, it's sort of seen as more attractive. And they 
will voice questions that they wouldn't want to voice to me, like, has anyone seen the timetable, of course they could have asked me but they don't. They just want to natter amongst themselves about it. (J)

She described how this had initially been a source of frustration because students asked questions (e.g. about assessments) to peers on Facebook but did not approach her. Eventually she joined the page to answer the questions but felt that she was 'actually breaking a barrier'. However, her students did not seem to mind this and were grateful for the answers she gave. As leader of the course, she came to see her presence on Facebook as advantageous because it provided the students with a sense of her presence even though she did not directly teach them. She perceived this is a relatively temporary state though and perceived Facebook as a 'generational thing' that might not work as well for students in five years time.

Other participants had found Facebook much more problematic. For Interviewee H, early experiences of using social networks through MySpace and later Facebook had been successful and enabled her to create 'a relaxed, fun, sense of a holistic relationship'. However, she started to be aware of problems relating to her professional and personal roles. In terms of her professional role, she was able to see students' personal messages that she would have preferred not to know about.

I was also seeing things that I didn't want to see and ... was having a hard time separating what I really wanted to use social media for from my professional role. And I felt increasingly uncomfortable with that actually, where you see, on the news reel, fights between students, God, do I intervene, what do I do, you've seen a student posting late at night in real distress, I've seen that, is it part of my role, what do I do? (H) 
Interviewee H's use of technology reflected her care for her students but in this case, there was a conflict between her responsibilities as a 'caring professional' and her own personal life. Similarly, she found her own personal use of social media was affected because if she wanted to use Facebook while on leave or late at night, a student could see her and contact her.

Students were also aware of the distinction between their personal and professional lives and Interviewee $\mathrm{H}$ and her colleagues had identified that some students did not want their university lecturers so closely connected with their life outside of study and were communicating a sense of 'back off here...this is not the space for you to enter' (H). While other students were more willing to cross professional and personal boundaries:

The problem with social media, if there are students who are, as you say, blur those boundaries or want those boundaries blurred for whatever number of reasons and there are many, having a social space is going to encourage it and as we all know the boundaries online are different in any case and they are harder to reinforce, I think. Much harder. (H)

These examples illustrate the range of factors that influence lecturers' decisions about technology. The initial desire to create a social space reflects the professional identity of the lecturer and her desire to build relationships with and between her students. However, maintaining this professional identity also led to her ending her experimentation with Facebook. Simultaneously, the wider context of developments in how students used technology in their lives outside of teaching was perceived as a reason for the failure of discussion forums and later Facebook as social learning spaces. The account demonstrates how this lecturer had tried to respond to the ways her students used 
technology and be sensitive to students' digital lives and culture but how, in the end, this was not what the students had wanted.

Research into students' perspectives of using Facebook in Higher Education has shown that students may feel uncomfortable if they believe their social life and study life are being blended (see the review by Manca \& Ranieri, 2013) and that they may be concerned about their privacy (e.g. Wang, Woo, Quek, Yang, \& Liu, 2013). This paper provides more evidence for this in the reports from lecturers of the reactions they have encountered but also extends these concerns to the lecturers themselves.

The quality of lecturers' participation and 'social presence' (Savvidou, 2013) in online learning situations is an important factor in their success. For example, Cramp (2015) suggests that emotional involvement is important for developing meaningful dialogue in digital learning spaces and that 'kindness' could be a decisive factor in achieving this. While Albayrak and Yildirim (2015) discuss how in a successful use of Facebook, students commented on the timeliness of responses from the course instructor via Facebook as opposed to other methods of communication. They note that this was because the instructor increased her availability. While Albayrak and Yildirim note the benefits for students, this study shows that this increased availability can have unwanted implications for lecturers.

While Veletsianos, Kimmons, and French (2013) study of the educational social network Elgg found that one of their participants believed that this technology "did not allow her to cultivate the types of relationships with her students that she was used to." (p271). Here the problem was the opposite. It was not that the lecturers could not cultivate 
relationships but that the relationships went beyond the professional relationship desired.

\section{Conclusions}

The data considered in this study is limited due to the small sample (eleven participants across three universities) and the experiences of ceasing to use technology that are described here should not be generalised to the wider body of university lecturers. However, the detailed nature of the narratives produced has illustrated the complex reasons that can underpin apparently simple decisions to stop using technology in teaching and highlights the 'messy realities' (Selwyn, 2010) of educational technology use.

The paper has demonstrated the range of different influences on lecturers' non-use of technology and has identified three situations in which lecturers cease to technology: where older technologies are replaced by newer ones; following unsuccessful experiences; and where there are changes of context.

Sometimes, lecturers make decisions to replace an out-dated technology because they have found a new technology that they consider 'better' in some way than what they used before or just 'newer'. The data here have shown that this is sometimes voluntary but also that such changes are sometimes forced on lecturers. As a result, some lecturers feel that they have limited choice about their technology use and are prevented from using technologies that they believed were beneficial for their students. These tensions between an individual's desire to use or not use technology and the institutional context in which they work may reflect physical constraints (the technology is not available any more) or more subtle social constraints (e.g. unwritten departmental or institutional expectations). 
This is further complicated by the way in which replacing a technology may lead to replacing the processes or skills that were used with that earlier technology. This requirement to 'un-learn' skills or practices may be an additional barrier to the adoption of new technology even if that technology may have been envisioned as a direct replacement for an existing tool. Thus educational technologies are shown not to be simply neutral tools that can be picked up and discarded at will by their users and that we should not ignore the unintended consequences of using technology (Burbules and Callister, 2000). The participants sometimes described what was lost when a technology was replaced supporting Kanuka and Rourke's suggestion "that technologies represent both losses and gains to higher education" (2008, p14).

As well as replacing technologies, lecturers also stopped using technology after unsuccessful experiences but this was not an automatic consequence of failure. Rather, the experiences of these lecturers have shown how instances where using technology was unsuccessful can be interpreted in different ways. Shelton (2014) distinguishes between educational technologies that have been adopted and become 'core' to an individuals' teaching and those which, though adopted, remain 'marginal' to practice. Applying these categories here, we can see that problems with using established or 'core' technologies were frustrating but they did not lead to the technology being abandoned altogether. Problems with less well-established technology while at the 'confirmation' stage of adoption could lead to the experiment with technology being discontinued. However, once a technology had been adopted, even problems with less well-established technologies would not necessarily lead to them being abandoned if there was sufficient reason to expect them to work more effectively in the future. In these cases, some 
participants attributed the problems that they faced to their own lack of technology skills.

As Trowler (2008) notes, uses of technology are 'socially and historically conditioned' (p. 32) and this study shows how technology use or non-use is closely related to wider cultural values and attitudes. Participants chose to stop using technology in response to their perceptions of the students they worked with. These could be perceptions of students' skills and the level of support they required but also perceptions of how technologies interest and engaged the groups they worked with. The connection between social context and technology used is seen most clearly in the example of how participants worked with social networks. Social media, such as Facebook, could challenge the boundaries between lecturers' home and work lives and prove an uncomfortable experience for lecturers.

Overall, the results of this study show that the adoption of new technology is not the end of the story. Continued implementation of technology depends on technical and social factors and is more than simple replacement with something newer. It demonstrates that technology is used within a broad social context by individuals with differing degrees of perceived agency.

Research into technology adoption has hitherto focused on the introduction of new devices or software and has been concerned with the perceptions that teachers hold about these new technologies, particularly regarding its ease of use and usefulness (e.g. Davis, et al., 1989). While the data presented in this paper is only sufficient to suggest tentative conclusions, it is suggestive that the conceptual model underpinning models of technology adoption is incomplete. This paper has shown that the perceptions held about 
existing technologies are important too and that new technologies are introduced not into a vacuum but into a context characterised by successful or unsuccessful technology use. The author would suggest that in order to understand and evaluate changes in uses of technology a conceptual framework is required that can account for the rejection or abandonment of previous technologies as well as the adoption or integration of the new. Such a framework needs to account for both voluntary and involuntary examples of ceasing to use technology and contain the three situations of replacement, failure and contextual change identified here.

Considering both the institutional and cultural context also helps to understand some of the challenges of teaching with technology. While this paper has highlighted some of the 'losses' that lecturers associated with giving up an older technology, it has also shown that re-introducing older technology could be problematic as the wider context may lead to students viewing this as obsolete. It remains a challenge for instructional designers and technologists to create new technologies that retain the most useful elements of the things they replace.

Overall, this study highlights the need for longitudinal studies of technology that consider how technologies are used over extended periods of time and for researchers to revisit early adopters of technology to see what has happened since pilot studies were published. In some cases, this may identify actions that could be taken by academic developers to support continued use of a technology and, in other cases, it may identify areas in which new approaches or technologies are emerging. Although the data here is insufficient to identify and disciplinary or individual patterns of non-use, these could be a useful avenue 
for future research. While it is natural for studies of technology adoption to focus on new technologies, the study is also a reminder that established technologies are still worth researching, particularly if we wish to avoid repeating past mistakes. 


\section{References}

Agbatogun, A. O. (2013). Interactive digital technologies' use in Southwest Nigerian universities. Educational Technology Research and Development, 61(2), 333-357. doi: $10.1007 / \mathrm{s} 11423-012-9282-1$

Albayrak, D., \& Yildirim, Z. (2015). Using Social Networking Sites for Teaching and Learning: Students' Involvement in and Acceptance of Facebook(R) as a Course Management System. Journal of Educational Computing Research, 52(2), 155179. doi: 10.1177/0735633115571299

Aydin, S. (2012). A review of research on Facebook as an educational environment. Educational Technology Research and Development, 60(6), 1093-1106. doi: 10.1007/s11423-012-9260-7

Bakioglu, A., \& Hacifazlioglu, O. (2007). Lecturers' and Students' attitudes Towards the Use of Technology in Lectures: No Taboos, More Thinking. Paper presented at the ISATT 2007 Conference, Ontario, Canada.

Booth, S., \& Hultén, M. (2003). Opening dimensions of variation: An empirical study of learning in a Web-based discussion. Instructional Science, 31(1), 65-86.

Bothma, C. H., \& Cant, M. C. (2011). Adopting learning technologies: from belief to practice. Educational Studies, 37(4), 375-389. doi:

$10.1080 / 03055698.2010 .511697$

Brill, J. M., \& Galloway, C. (2007). Perils and promises: University instructors' integration of technology in classroom-based practices. British Journal of Educational Technology, 38(1), 95-105. doi: 10.1111/j.1467-8535.2006.00601.x

Buchanan, T., Sainter, P., \& Saunders, G. (2013). Factors affecting faculty use of learning technologies: implications for models of technology adoption. Journal of Computing in Higher Education, 25(1), 1-11. doi: 10.1007/s12528-013-9066-6

Burbules, N. C., \& Callister, T. A. (2000). Watch IT : the risks and promises of information technologies in education. Boulder, Colo ; Oxford: Westview.

Cassady, J. C. (1998). Student and Instructor Perceptions of the Efficacy of ComputerAided Lectures in Undergraduate University Courses. Journal of Educational Computing Research, 19(2), 175-189. doi: 10.2190/xy1k-0bet-jf6c-wtpl 
Charmaz, K. (2006). Constructing grounded theory : a practical guide through qualitative analysis. London: SAGE.

Craig, R. J., \& Amernic, J. H. (2006). PowerPoint Presentation Technology and the Dynamics of Teaching. Innovative Higher Education, 31(3), 147-160. doi: 10.1007/s10755-006-9017-5

Cramp, A. (2015). Meaningful dialogue in digitally mediated learning for in-service teacher development. Technology, Pedagogy and Education, 24(1), 1-16. doi: 10.1080/1475939x.2013.822417

Davis, F. D., Bagozzi, R. P., \& Warshaw, P. R. (1989). User acceptance of computer technology: A comparison of two theoretical models. Management Science, 35(8), 982-1003.

Flick, U. (2009). An Introduction to Qualitative Research (4th Edition). Sage Publications: London.

Kanuka, H., \& Rourke, L. (2008). Exploring amplifications and reductions associated with e-learning: conversations with leaders of e-learning programs. Technology, Pedagogy and Education, 17(1), 5-15. doi: 10.1080/14759390701847401

Kay, H. (1979). Keynote address. Educational technology 20 years on - Sheffield revisited. In G. T. Page \& Q. Whitlock (Eds.), Aspects of Educational Technology XIII - Educational Technology Twenty Years On (pp. 11-18). London: Kogan Page.

Kidd, T. T. (2010). Butterfly under a pin: Exploring the voices and stories told of faculty who adopt ICT's for teaching and learning practices. Education and Information Technologies, 15(3), 155-170. doi: 10.1007/s10639-009-9102-3

Kirkwood, A. (2009). E-learning: you don't always get what you hope for. Technology, Pedagogy and Education, 18(2), 107-121. doi: 10.1080/14759390902992576

Manca, S., \& Ranieri, M. (2013). Is it a tool suitable for learning? A critical review of the literature on Facebook as a technology-enhanced learning environment. Journal of Computer Assisted Learning, 29(6), 487-504. doi: 10.1111/jcal.12007

Rogers, E. M. (1962). Diffusion of innovations. New York,: Free Press of Glencoe. 
Savvidou, C. (2013). 'Thanks for sharing your story': the role of the teacher in facilitating social presence in online discussion. Technology, Pedagogy and Education, 22(2), 193-211. doi: 10.1080/1475939x.2013.787267

Selwyn, N. (2007). The use of computer technology in university teaching and learning: a critical perspective. Journal of Computer Assisted Learning, 23(2), 83-94. doi: 10.1111/j.1365-2729.2006.00204.x

Selwyn, N. (2010). Looking beyond learning: notes towards the critical study of educational technology. Journal of Computer Assisted Learning, 26(1), 65-73. doi: $10.1111 / \mathrm{j} .1365-2729.2009 .00338 . \mathrm{x}$

Shelton, C. (2014). "Virtually mandatory": A survey of how discipline and institutional commitment shape university lecturers' perceptions of technology. British Journal of Educational Technology, 45(4), 748-759. doi: 10.1111/bjet.12051

Šumak, B., Heričko, M., \& Pušnik, M. (2011). A meta-analysis of e-learning technology acceptance: The role of user types and e-learning technology types. Computers in Human Behavior, 27(6), 2067-2077. doi: 10.1016/j.chb.2011.08.005

Szabo, A., \& Hastings, N. (2000). Using IT in the undergraduate classroom: should we replace the blackboard with PowerPoint? Computers \& Education, 35(3), 175187. doi: http://dx.doi.org/10.1016/S0360-1315(00)00030-0

Trowler, P. (2008). Cultures and Change in Higher Education: Theories and Practice. Basingstoke: Palgrave Macmillan.

Veletsianos, G., Kimmons, R., \& French, K. D. (2013). Instructor experiences with a social networking site in a higher education setting: expectations, frustrations, appropriation, and compartmentalization. Educational Technology Research and Development, 61(2), 255-278. doi: 10.1007/s11423-012-9284-z

Venkatesh, V., Morris, M. G., Davis, G. B., \& Davis, F. D. (2003). User acceptance of information technology: Toward a unified view. MIS Quarterly, 27(3), 425-478.

Wang, Q., Woo, H. L., Quek, C. L., Yang, Y., \& Liu, M. (2012). Using the Facebook group as a learning management system: An exploratory study. British Journal of Educational Technology, 43(3), 428-438. doi: 10.1111/j.1467-8535.2011.01195.x

Weller, M. (2011). The digital scholar : how technology is transforming scholarly practice. London: Bloomsbury Academic. 
Welsh, M. (2012). Student perceptions of using the PebblePad e-portfolio system to support self- and peer-based formative assessment. Technology, Pedagogy and Education, 21(1), 57-83. doi: 10.1080/1475939x.2012.659884

West, R. E., Waddoups, G., \& Graham, C. R. (2007). Understanding the experiences of instructors as they adopt a course management system. Educational Technology Research and Development, 55(1), 1-26. doi: 10.1007/s11423-006-9018-1

Westberry, N., McNaughton, S., Billot, J., \& Gaeta, H. (2014). Resituation or resistance? Higher education teachers' adaptations to technological change. Technology, Pedagogy and Education, 24(1), 101-116. doi: 10.1080/1475939x.2013.869509

Zhu, C. (2013). Organisational culture and technology-enhanced innovation in higher education. Technology, Pedagogy and Education, 24(1), 65-79. doi:

10.1080/1475939x.2013.822414 
Table 1 Interview Sample

\begin{tabular}{|l|l|l|l|l|l|l|}
\hline & HEI & $\begin{array}{l}\text { Subject } \\
\text { discipline }\end{array}$ & Gender & Age & Role & Contract \\
\hline A & 1 & Nursing & Female & $40-49$ & $\begin{array}{l}\text { Senior } \\
\text { Lecturer }\end{array}$ & $\begin{array}{l}\text { Full-time } \\
\text { permanent }\end{array}$ \\
\hline B & 2 & Psychology & Male & $50-59$ & $\begin{array}{l}\text { Senior } \\
\text { Lecturer }\end{array}$ & $\begin{array}{l}\text { Full-time } \\
\text { permanent }\end{array}$ \\
\hline C & 2 & $\begin{array}{l}\text { Biological } \\
\text { sciences }\end{array}$ & Male & $40-49$ & $\begin{array}{l}\text { Senior } \\
\text { Lecturer }\end{array}$ & $\begin{array}{l}\text { Full-time } \\
\text { permanent }\end{array}$ \\
\hline D & 2 & Education & Male & $50-59$ & Professor & $\begin{array}{l}\text { Full-time } \\
\text { permanent }\end{array}$ \\
\hline E & 3 & Education & Female & $30-39$ & $\begin{array}{l}\text { Senior } \\
\text { Lecturer }\end{array}$ & $\begin{array}{l}\text { Full-time } \\
\text { permanent }\end{array}$ \\
\hline F & 1 & Law & Male & $30-39$ & Lecturer & $\begin{array}{l}\text { Part-time } \\
\text { permanent }\end{array}$ \\
\hline G & 3 & $\begin{array}{l}\text { Childhood } \\
\text { Studies }\end{array}$ & Female & $40-49$ & Lecturer & $\begin{array}{l}\text { Full-time } \\
\text { temporary }\end{array}$ \\
\hline H & 3 & English & Female & $40-49$ & $\begin{array}{l}\text { Senior } \\
\text { Lecturer }\end{array}$ & $\begin{array}{l}\text { Full-time } \\
\text { permanent }\end{array}$ \\
\hline I & 2 & $\begin{array}{l}\text { Subjects } \\
\text { allied to } \\
\text { medicine }\end{array}$ & Female & $40-49$ & $\begin{array}{l}\text { Senior } \\
\text { Lecturer }\end{array}$ & $\begin{array}{l}\text { Full-time } \\
\text { permanent }\end{array}$ \\
\hline J & 1 & $\begin{array}{l}\text { Creative arts } \\
\text { \& design }\end{array}$ & Female & $50-59$ & Reader & $\begin{array}{l}\text { Full-time } \\
\text { permanent }\end{array}$ \\
\hline K & 3 & Biomechanics & Male & $30-39$ & $\begin{array}{l}\text { Senior } \\
\text { Lecturer }\end{array}$ & $\begin{array}{l}\text { Full-time } \\
\text { permanent }\end{array}$ \\
\hline
\end{tabular}

